\title{
An important complication of upper cervical spine fracture: a case report
}

\author{
D. W. HODGKINSON, D. J. BAMFORD*, \& \\ P. DRISCOLL \\ Departments of Accident and Emergency Medicine and *Orthopaedic Surgery, \\ University of Manchester, Hope Hospital, Eccles Old Road, Salford
}

\section{SUMMARY}

A case report is presented of a patient who sustained a high cervical spine fracture, the possible mechanisms of injury and details of the fracture are discussed. The patient developed bilateral vagal nerve palsies $48 \mathrm{~h}$ after the accident. This complication was only recognized after dysphagia and an aspiration pneumonia developed. The complication of aspiration pneumonia was preventable. Meticulous and repeated examination of the cranial nerve function in this type of injury is recommended. Normal feeding should commence only when the cranial nerve function has been shown to be normal after repeated examination.

\section{INTRODUCTION}

A case of a cervical spine injury is reported with fractures involving C1 and C2 which presented recently. Several unusual features of this injury are discussed. Neurological assessment in such patients often includes detailed examination of spinal cord and peripheral nerve function below the level of the injury and scant attention is paid to neurological function above the level of the injury.

\section{CASE REPORT}

A 60-year-old man was seen in the accident \& emergency (A\&E) department having fallen 8 feet from a ladder in his garden. There was no loss of consciousness and he reported that his shoulders hit the ground first. For several seconds immediately

Correspondence: Mr D. W. Hodgkinson, Department of Accident and Emergency Medicine, Hope Hospital, Eccles Old Road, Salford M6 8HD, U.K. 
after the fall he had no feeling in his arms but he was able to get to his feet ang walk into the house to call an ambulance. The ambulance crew attending applied stiff cervical collar and transported him lying flat on a scoop stretcher.

On arrival at the hospital his only complaint was of severe neck pain. He hat abrasions over his right shoulder. Neurological examination revealed slight weak? ness in the triceps and biceps of both arms (MRC Grade 4) with blunting of the reflexes throughout all four limbs. There was no sensory deficit.

Plain radiographs of the cervical spine were performed (Fig. 1) and initiall $\overrightarrow{8}$ these were thought to be normal. He was admitted in view of the rather worrying history and clinical findings and nursed supine with a stiff cervical collar. A C 5 scan of his upper cervical spine was performed on the second day of admission. It showed the fracture of $\mathrm{Cl}$ extending obliquely through the right lateral mass t\& the left posterior arch (not shown) and a fracture of $\mathrm{C} 2$ which passed transversel through the posterior part of the body of the vertebra (Fig. 2). In retrospect the C. and $\mathrm{C} 2$ fractures could be seen on the initial plain radiographs.

Also on the second day after admission whilst lying flat the patient was allowed to eat and drink. He developed dysphagia and aspirated. This resulted in a severê bronchopneumonia requiring supplementary oxygen, intensive physiotherap $\vec{y}$ and intravenous antibiotics before recovering. On examination, he had bilaterab vagal nerve palsies with partial injury to the glossopharyngeal nerves on botto sides and complete loss of function of his soft palate. Prior to this, no cranial nerve examination had been documented, though there had been repeated detaipe

examination of the peripheral nervous system.
The patient required feeding via a nasogastric tube for several weeks. Flexiont and extension views of his neck (Fig. 3) were performed 7 days after the incide

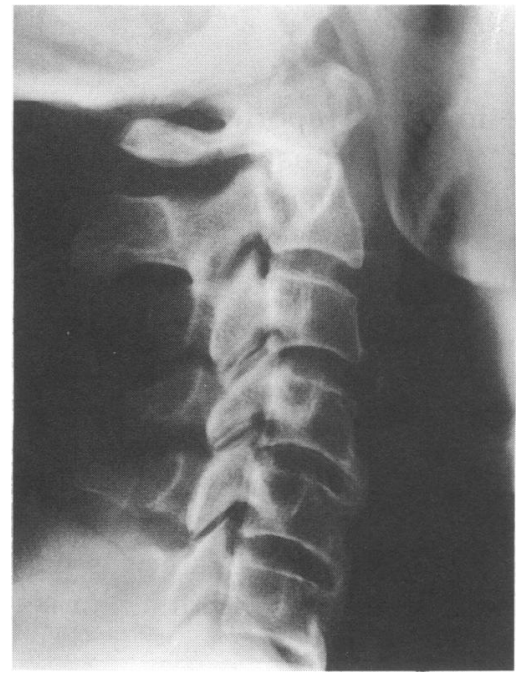

Fig. 1. Initial plain lateral $X$-ray of neck. 


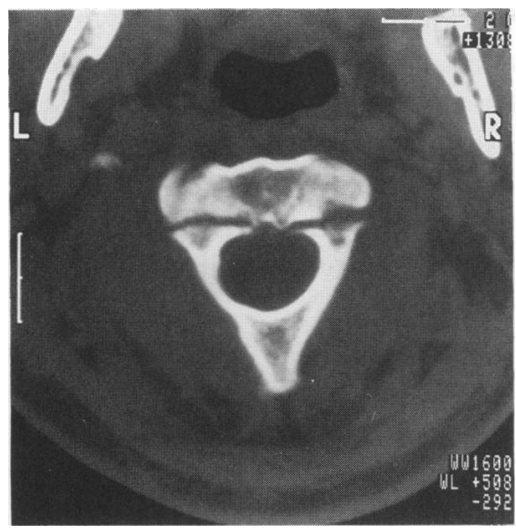

Fig. 2. CT Scan showing fracture passing through the body of $\mathrm{C} 2$.

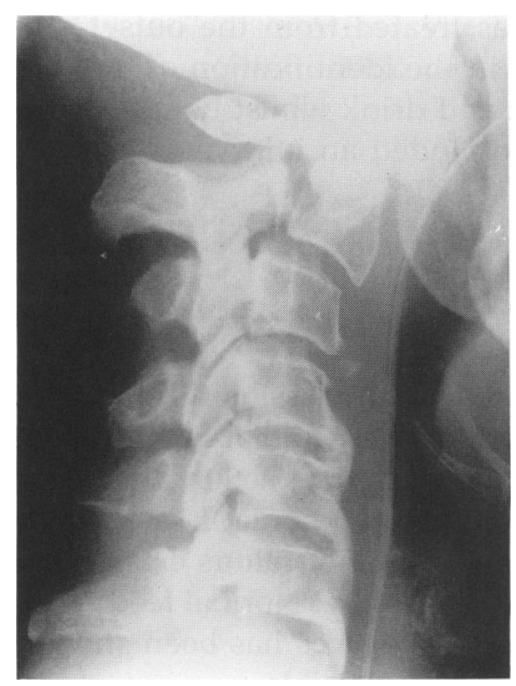

Fig. 3. Flexion views clearly demonstrating the fracture (note the feeding tube).

when his condition had improved suficiently for him to be moved. These showed the neck to be unstable in the flexed position, but reduced in neutral. On this basis, he was treated conservatively in a Doll collar and union had occurred by 12 weeks. Normal power returned to his arms and at 3 months his dysphagia had almost completely resolved and he was eating normally.

\section{DISCUSSION}

The term 'Hangman's fracture' is used to describe bilateral avulsion fractures through the pars interarticularis of $\mathrm{C} 2$ seperating the neural arch from the axis 
body without injury to the odontoid peg and forward subluxation of $\mathrm{C} 2$ on $\mathrm{C} 3 \frac{\mathrm{D}}{\mathrm{B}}$ (Schneider et al. 1965). As can be seen in Fig. 2 the fracture involves the body of $\mathrm{C} 2$ rather than the pedicles and consequently is similar to the case described by? Marotta et al. (1990). Associated posterior $\mathrm{Cl}$ arch fractures have previously been ${ }_{\mathrm{s}}^{*}$ described by Levine \& Edwards (1986). Most authors postulate the mechanism of injury in such cases as being hyperextension (Harris et al. 1986). In this case the patient clearly described falling backwards, striking the ground with his shoulder therefore sustaining a flexion injury.

The delayed onset of neurological symptoms has been described previouslye by Lyness \& Simone (1978). The cause of cranial nerve damage is thought to $\overrightarrow{0}$ be ischaemia secondary to vertebral artery occlusion. The sequelae range from $\vec{\omega}$ asymptomatic in unilateral injuries to Wallenberg's syndrome and various cranialo nerve palsies and fatal brain stem injury. The 'Hangman's fracture' can also cause $e^{\mathbb{D}}$. dysphagia and visual disturbance in non-fatal cases (Schneider et al. 1965). In thiscase there was a high index of suspision that there had been a significant injury tow the cervical spine despite the plain radiographs being initially thought to bew normal and the patient was treated from the outset with cervical spine immobil-o ization. There was a delay in the identification of the cranial nerve lesions and the patient was allowed to eat and drink whilst lying flat before repeated examinations of the cranial nerves had excluded an injury.

\section{CONCLUSION}

It is necessary to be aware of the possibility of delayed neurological deficit ins spinal trauma, in particular, delayed cranial nerve deficit in cases of high cervicalo spine injury. Only then can appropriate action be taken to prevent the potentiallyö lethal complication of aspiration pneumonia. It is recommended that these patients are observed very closely and that meticulous examination of both the cranial ando peripheral nerves are made repeatedly. Normal feeding should only be commenced when the function of the cranial nerves has been shown to be normal throughout the period when deterioration is possible.

\section{REFERENCES}

Harris J. H., Edeiken-Monroe B. \& Kopaniky D. R. (1986) A practical classification of acute cervicald spine injuries. Orthopedic Clinics of North America 17(1), 15-30.

Levine A. M. \& Edwards C. C. (1986) Treatment of injuries in the C1 - C2 complex. Orthopedic ClinicsN of North America 17(1), 31-44.

Lyness S. S. \& Simeone F. A. (1978) Vascular complications of upper cervical spine injuries. Orthopedic $\mathrm{N}$ Clinics of North America 9(1), 1029-1038.

Marotta T. R., White L., TerBrugge K. G., Spiegel S. M., Stevens J. K., \& Tator, C. M. (1990) An unusualO type of Hangman's Fracture. Neurosurgery 26(5), 848-851.

Schneider R. C., Livingston K. E., Cave A. J. E. \& Hamilton, G. (1965) Hangman's Fracture of the cervical spine. Journal of Neurosurgery 22, 141-154. 